\title{
Kidney stone analysis: "Give me your stone, I will tell you who you are!"
}

\author{
Jonathan Cloutier $\cdot$ Luca Villa $\cdot$ Olivier Traxer · \\ Michel Daudon
}

Received: 9 September 2014 / Accepted: 10 November 2014 / Published online: 3 December 2014

(C) The Author(s) 2014. This article is published with open access at Springerlink.com

\begin{abstract}
Introduction Stone analysis is an important part in the evaluation of patients having stone disease. This could orientate the physician toward particular etiologies.

Material and methods Chemical and physical methods are both used for analysis. Unfortunately, chemical methods often are inadequate to analyze accurately urinary calculi and could fail to detect some elements into the stone. Physical methods, in counterpart, are becoming more and more used in high-volume laboratories. The present manuscript will provide a review on analytic methods, and review all the information that should be included into an appropriate morpho-constitutional analysis.

Conclusion This report can supply an excellent summarization of the stone morphology and give the opportunity to find specific metabolic disorders and different lithogenic process into the same stone. Here, specific chemical types with their different crystalline phases are shown in connection with their different etiologies involved.
\end{abstract}

Keywords Urinary calculi $\cdot$ Stone morphology · Etiology $\cdot$ Stone analysis $\cdot$ Calcium oxalate $\cdot$ Calcium phosphate

J. Cloutier $\cdot$ L. Villa $\cdot$ O. Traxer

Urology Department, Tenon University Hospital, 4 rue de la

Chine, 75970 Paris Cedex 20, France

M. Daudon $(\bowtie)$

Service des Explorations Fonctionnelles, Tenon University Hospital, 4 rue de la Chine, 75970 Paris Cedex 20, France e-mail: michel.daudon@tnn.aphp.fr

\section{Introduction}

Over the last decades, urolithiasis has been increasingly diagnosed, and nowadays, it affects roughly $10 \%$ of the Western countries population [1-5]. Dramatic changes in dietary habits including a high protein and salt intake, and more recently a high consumption of carbonated beverage rich in fructose represent one of the major causes of an increased incidence of calcium oxalate renal stone, which now represents the most frequently diagnosed type of stone. [6-8]. However, several other factors may be implied in stone formation. Indeed, more than 100 chemical components have been identified in urinary calculi [9], and more than 100 different etiologies may be involved in stone formation. Among analytical methods for identifying the stone components, chemical and physical methods can be used. However, despite their low cost, chemical methods are often inadequate for accurately analyzing urinary calculi. They are unsuccessful to identify rare purine stones resulting from genetic disorders such as 2,8-dihydroxyadenine [10-12] or drug-induced calculi [13-15]. Moreover, they are unable to quantify the respective amount of each element in mixed stones and to differentiate accurately between the various crystalline phases of calcium oxalate or calcium phosphate that are related to very different biochemical and pathophysiological conditions [16-18].

\section{Physical analytic methods}

Among physical methods, X-ray diffraction (XRD) and Fourier transform infrared spectroscopy (FTIR) are currently used for stone analysis. They identify each component and provide semi-quantitative evaluation of their proportions within the stone. 


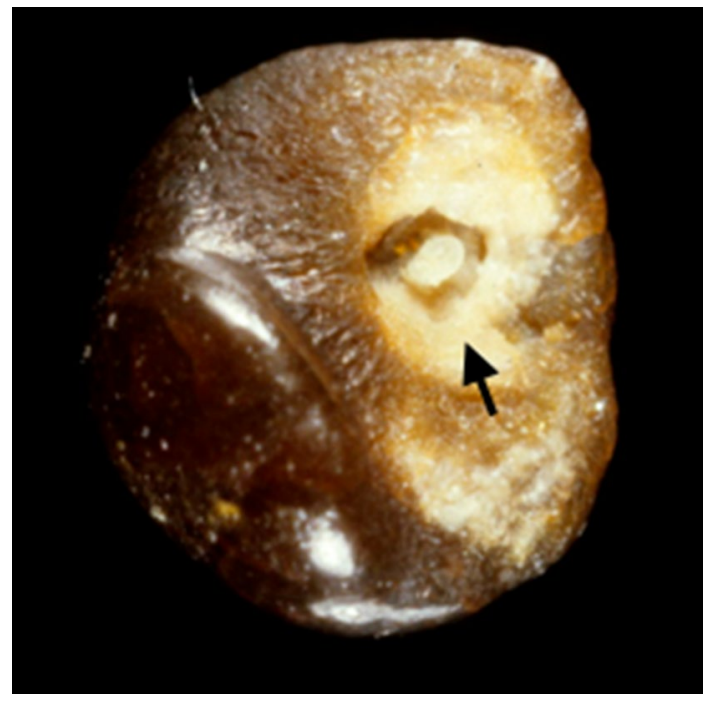

Fig. 1 Whewellite stone initiated from a carbapatite Randall's plaque (arrow)

These methods are able to identify non-calcium stones such as cystine, 2,8-dihydroxyadenine, xanthine, uric acid, urates, methyl-1 uric acid, struvite, proteins, lipids or drugs, as well as calcium oxalate $(\mathrm{CaOx})$ and/or calcium phosphate $(\mathrm{CaPh})$ stones. Because stones may remain several months or years in the urinary tract, they contain commonly (94\% in our experience) several components [19]. An accurate identification of minor components with their location in the stone is clinically relevant to assess environmental factors involved or to explain the lithogenic process (for example crystallization of $\mathrm{CaOx}$ from a $\mathrm{CaPh}$ Randall's plaque). Moreover, it could highlight marked changes in conditions with outbreak of new lithogenic process such as primary hyperparathyroidism, type 2 mellitus diabetes or urinary tract infection by urea-splitting bacteria (Figs. 1, 2, 3, 4).

Physical methods provide information on crystalline phases of the same chemical species that may imply different lithogenic conditions: for example, whewellite $(\mathrm{CaOx}$ monohydrate, $\mathrm{COM})$ and weddellite (CaOx dihydrate, $\mathrm{COD})$ among $\mathrm{CaOx}$ stones; carbapatite, brushite, or whitlockite among $\mathrm{CaPh}$ stones. A similar composition, for example $\mathrm{CaOx}$, may be the result of a variety of lithogenic processes, including diet imbalance, low diuresis, genetic or acquired diseases [9]. It is the same for crystalline phases: COM stones may correspond to hyperoxaluric states related to very different etiopathogenic conditions, such as primary hyperoxaluria, enteric hyperoxaluria, or idiopathic $\mathrm{CaOx}$ nephrolithiasis $[16,20]$. In contrast, COD stones are clearly related to hypercalciuria in a very high proportion of cases [16, 20, 21]. The corresponding stones exhibit distinct morphology easily identified in both surface and section (Fig. 5). Finally, the initial nucleation process could be related to another mechanism

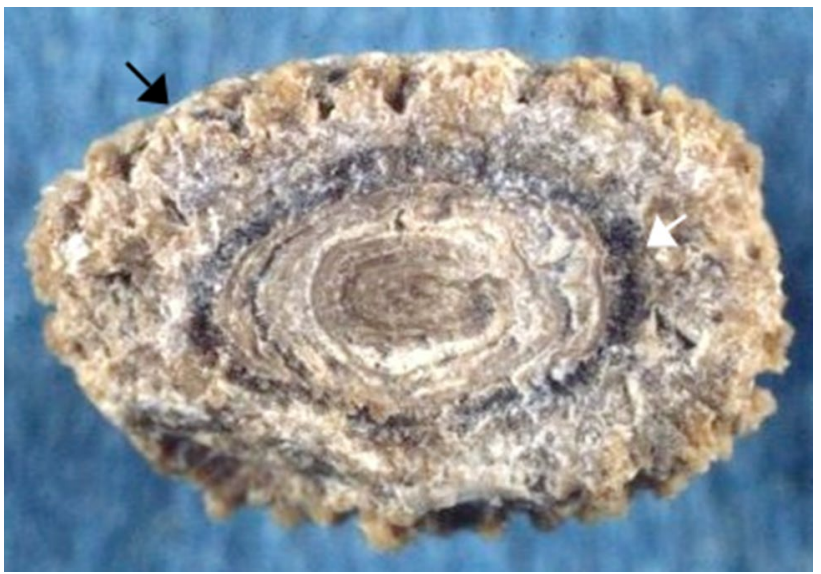

Fig. 2 Kidney stone from a child aged 9 years old. Examination of the stone section shows a mixed stone initiated by crystallization of ammonium hydrogen urate as a result of chronic diarrhea related to bowel infection while the child ate a vegetable diet providing insufficient protein and phosphorus intake. Ammonium urate was secondly covered by whewellite (white arrow) as a consequence of oxalate-rich diet and low water intake. The further coverage by a mixture of weddellite and carbapatite (black arrow) was the consequence of changes in life style resulting in an easy access to dairy products. The child developed hypercalciuria of dietary origin

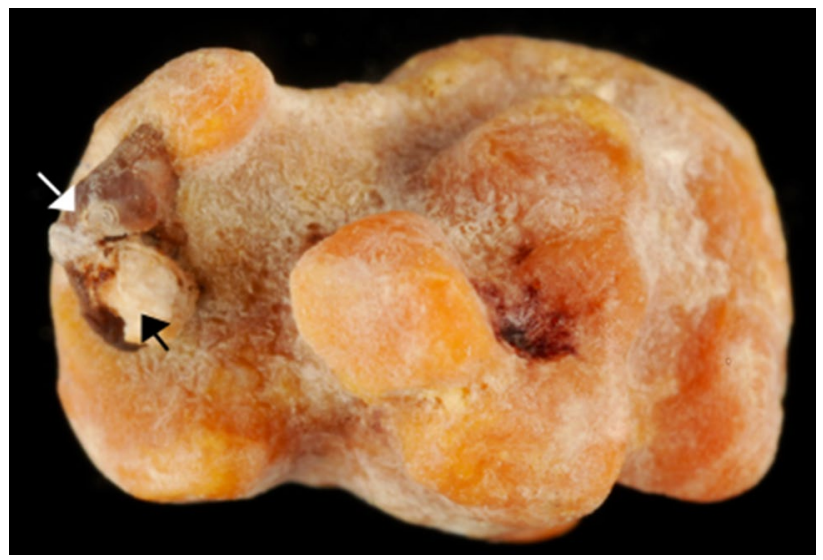

Fig. 3 Uric acid kidney stone in a man aged 58 years old. The patient had a BMI above $30 \mathrm{~kg} / \mathrm{m}^{2}$ and suffered a type 2 diabetes mellitus and hypertension. Uric acid was the consequence of metabolic syndrome and diabetes. However, stone analysis provided evidence that uric acid was secondly deposited on a whewellite stone (white arrow) and that the first step of stone formation was a carbapatite Randall's plaque (black arrow), suggesting the stone was initiated for a long time

(e.g., Randall's plaque) than the factors responsible for the subsequent stone growth. All these considerations raise the importance that the stone analysis should provide information on the stone morphology, chemical composition and crystalline phases, as well as their location within the stone.

Only physical methods can identify such a diversity of components. For this purpose, several techniques were 
proposed in routine practice [22], including X-ray powder diffraction [23], infrared spectroscopy [24], Raman spectroscopy [25, 26], scanning electron microscopy [27] or thermal analysis [28] and also stereomicroscopy for stone morphology $[9,20]$. Nowadays, infrared spectroscopy is extensively

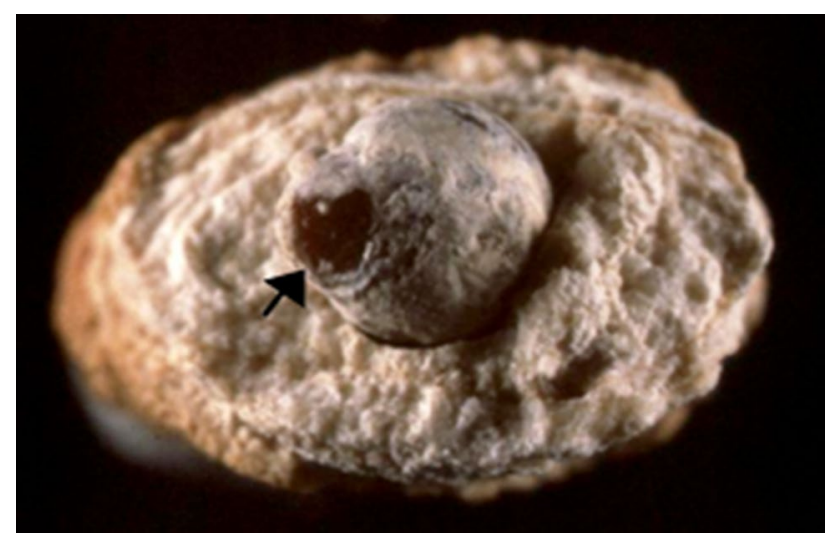

Fig. 4 Section of a stone presumably related to urinary tract infection. In fact, while the peripheral layers are made of a mixture of carbapatite and struvite as a consequence of chronic UTI, the core of the stone is made of pure whewellite, suggesting that metabolic factors are first involved in the stone process. Of note, the morphology of the initial whewellite stone shows a papillary imprint (arrow) which is highly suggestive of heterogeneous nucleation from a Randall's plaque (not visible) used for more than 300,000 stone analyses per year over the world. One limitation for some centers to use this technology can be the cost associated with the equipment, infrared spectroscopy is the less expensive, and X-ray powder diffraction and scanning electron microscopy are the most expensive.

\section{What information from stone analysis could be clinically relevant?}

A stone might be the first manifestation of numerous pathologies and metabolic disorders. The objective of stone analysis is to collect all relevant information from the stone helping the physician to establish the cause(s) of stone formation and growth. For that purpose, physicians may investigate blood and urine biochemistry of each stone former in order to identify metabolic disorders able to provide accurate information on a possible metabolic disease or risk factors involved in lithogenesis. Such metabolic investigation does not ensure the actual diagnosis of the lithogenic disease if stone composition does not match. Moreover, the stone composition during subsequent analysis can differ in up to $21 \%$ of cases, implicating the necessity to send for morpho-constitutional analysis every different stone events/treatments [29].

Thus, in addition to metabolic investigation, stone analysis is an essential step for the etiological diagnosis. In some cases, the metabolic disease implied in stone formation is
Fig. 5 Common stones made of calcium oxalate. Stone morphology is very different according to the crystalline phase: Calcium oxalate monohydrate corresponding to the stone subtype Ia (a surface; b section). Calcium oxalate dihydrate corresponding to the stone subtype IIa (c surface; d section)
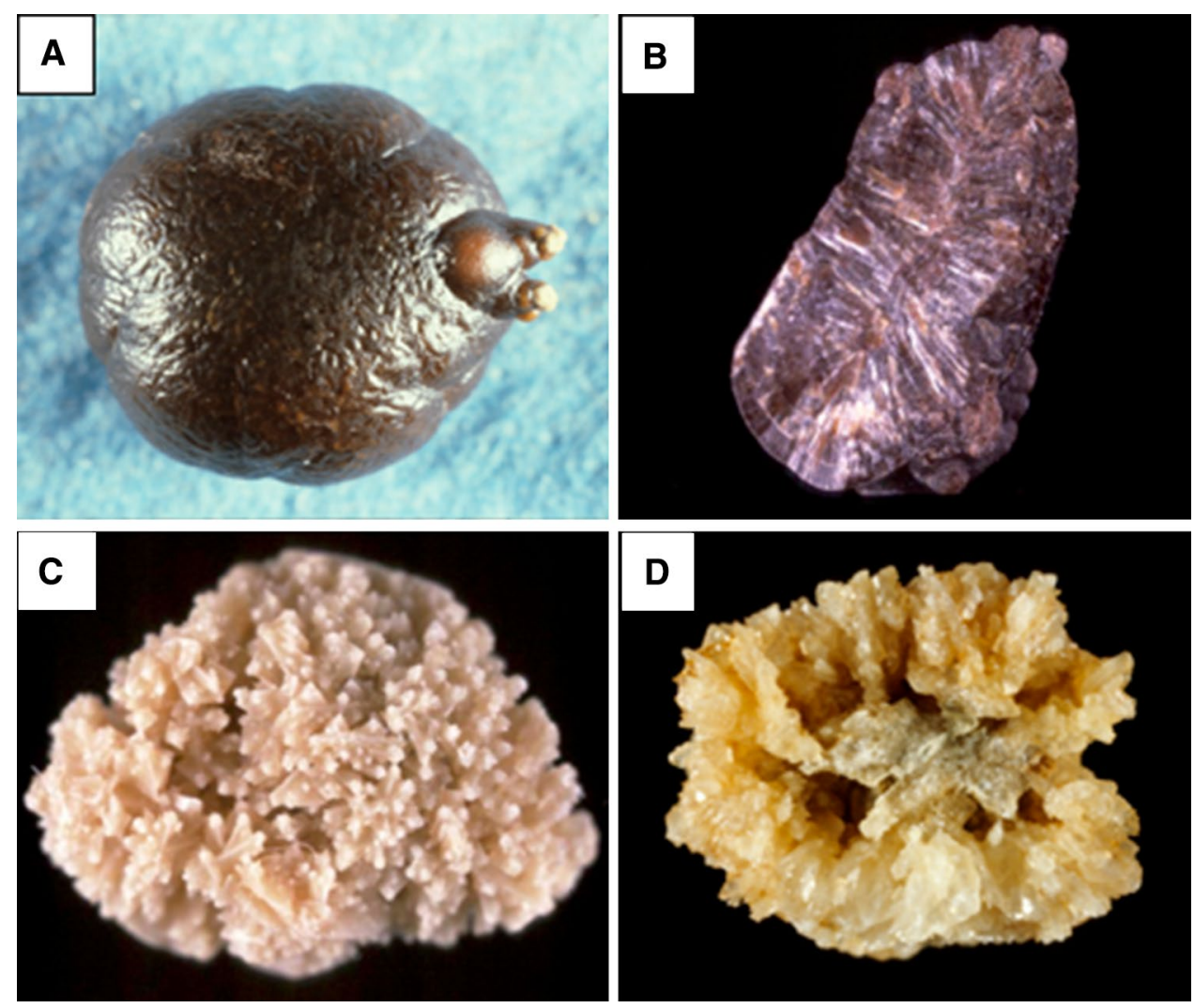
Table 1 Main relations observed between stone type, main component and etiology

\begin{tabular}{|c|c|c|c|c|}
\hline Morphological type & Subtype & Main components & \multicolumn{2}{|l|}{ Common causes } \\
\hline \multirow[t]{5}{*}{ I } & Ia & Whewellite & \multicolumn{2}{|c|}{ Dietary hyperoxaluria } \\
\hline & $\mathrm{Ib}$ & Whewellite & \multicolumn{2}{|c|}{ Stasis, low diuresis } \\
\hline & Ic & Whewellite & \multicolumn{2}{|c|}{ Primary hyperoxaluria type I } \\
\hline & Id & Whewellite & \multicolumn{2}{|c|}{ Malformative uropathy, stasis and confined multiple stones } \\
\hline & Ie & Whewellite & \multicolumn{2}{|c|}{ Enteric hyperoxaluria } \\
\hline \multirow[t]{3}{*}{ II } & IIa & Weddellite & \multicolumn{2}{|l|}{ Hypercalciuria } \\
\hline & IIb & Weddellite \pm whewellite & \multicolumn{2}{|c|}{ Hypercalciuria \pm hyperoxaluria \pm hypocitraturia } \\
\hline & IIc & Weddellite & \multicolumn{2}{|c|}{ Hypercalciuria, stasis and confined multiple stones } \\
\hline \multirow[t]{4}{*}{ III } & IIIa & Uric acids & \multicolumn{2}{|c|}{ Low urine $\mathrm{pH}$ and stasis } \\
\hline & IIIb & Uric acids & \multicolumn{2}{|c|}{ Metabolic syndrome, diabetes } \\
\hline & IIIc & Various urates & \multicolumn{2}{|c|}{ Hyperuricosuria and alkaline urine, UTI } \\
\hline & IIId & Ammonium urate & \multicolumn{2}{|c|}{ Hyperuricosuria and diarrhea } \\
\hline \multirow[t]{5}{*}{ IV } & IVa1 & Carbapatite & \multicolumn{2}{|c|}{ Hypercalciuria, UTI } \\
\hline & IVa2 & Carbapatite & \multicolumn{2}{|c|}{ Distal renal tubular acidosis } \\
\hline & IVb & Carbapatite & \multicolumn{2}{|c|}{ UTI, hypercalciuria. Etiology depends on minor components identified in the stone } \\
\hline & IVc & Struvite & \multicolumn{2}{|c|}{ UTI by urease-splitting bacteria } \\
\hline & IVd & Brushite & \multicolumn{2}{|c|}{ Hypercalciuria, PHPT, phosphate leak } \\
\hline \multirow[t]{2}{*}{ V } & Va & Cystine & \multicolumn{2}{|l|}{ Cystinuria } \\
\hline & $\mathrm{Vb}$ & Cystine & \multicolumn{2}{|c|}{ Cystinuria + inadequate therapy } \\
\hline \multirow[t]{3}{*}{ VI } & VIa & Proteins & \multicolumn{2}{|c|}{ Chronic pyelonephritis } \\
\hline & VIb & Proteins & \multicolumn{2}{|c|}{ Proteinuria, drugs, clots } \\
\hline & VIc & Proteins & \multicolumn{2}{|c|}{ ESRF and excessive calcium + vitamin D supplementation } \\
\hline \multicolumn{5}{|l|}{ Main associations } \\
\hline \multicolumn{2}{|l|}{ Ia or Ib + IIa or IIb } & \multicolumn{2}{|c|}{ Whewellite + weddellite } & Intermittent hyperoxaluria and hypercalciuria (dietary origin) \\
\hline $\mathrm{Ia}+\mathrm{IVa} 1$ & & Whewellite + carba] & tite & Randall's plaque, medullary sponge kidney \\
\hline IIa or IIb + IVa1 & & Weddellite + carbap & & Absorptive or resorptive hypercalciuria \\
\hline $\mathrm{Ia}$ or Ib + IIa or IIb - & $\mathrm{IVa}$ or IVb & Whewellite + wedd & lite + carbapatite & Hyperoxaluria + hypercalciuria, medullary sponge kidney \\
\hline $\mathrm{Ia}+\mathrm{IIIb}$ & & Whewellite + uric a & & Hyperoxaluria + metabolic syndrome \\
\hline
\end{tabular}

UTI urinary tract infection, $P H P T$ primary hyperparathyroidism, ESRF end-stage renal failure

unrecognized by standard metabolic investigations while the stone may contain particular component allowing diagnosis unambiguously [12-15]. An example is adenine phosphoribosyltransferase deficiency revealed by a stone made of 2,8-dihydroxyadenine. To obtain this result, physical methods for stone analysis are required.

Stone analysis has to report qualitative and quantitative information regarding crystalline phases, their location within the stone and structural characteristics (morphoconstitutional analysis) $[9,20]$. Such procedure consists in examining the surface and cross-sectional morphology to summarize stone features as a morphological type that can be related to metabolic disorders and diseases. Moreover, determining accurately the composition of all parts of the stone (the core, inner layers, peripheral layers and surface) is essential. Finally, a global qualitative analysis from the whole stone (or a fragment of the stone) with the relative proportions of all components identified by sequential analysis is recommended.

Morphological characteristics and the corresponding morphological types have been already described [9, 20]. In Table 1, the various types of stones are summarized, their corresponding main crystalline phase and the common causes associated with each stone subtype. About $98 \%$ of urinary calculi are incorporated according to that classification. If a stone cannot be classified, two explanations should be considered: the chemical composition (e.g., dihydroxyadenine, xanthine, atazanavir, sulfadiazine...) or the cause is very uncommon [30]. Because calculi are frequently made of several crystalline phases, it is not surprising to find a mixture of different subtypes related to the different crystalline phases. Among the principal associations, finding binary mixtures such as COM and COD or ternary mixtures including $\mathrm{COM}, \mathrm{COD}$ and carbapatite are 


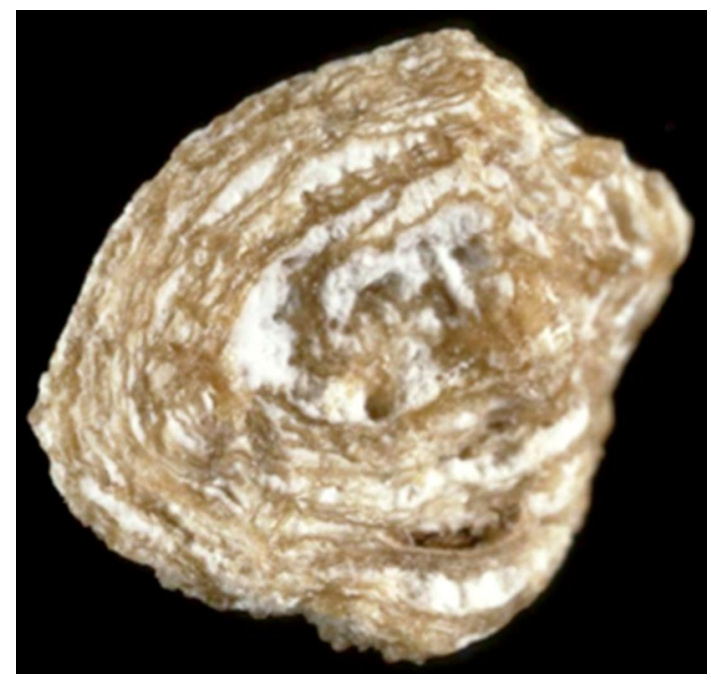

Fig. 6 Type IIa + IVa mixed stone made of alternate layers of weddellite and carbapatite. Such a morphology and composition is highly suggestive of hypercalciuria. Of note, more than $50 \%$ of calcium stones related to primary hyperparathyroidism exhibit such a structure

counting together for a quarter of cases in our experience (Fig. 6).

The main limitation for an accurate stone analysis is the progress in flexible ureteroscopy with laser energy used to fragment a significant part of the stone, thus providing only small piece(s) for analysis. However, remembering that $60-80 \%$ of urinary calculi pass spontaneously, they should be submitted to a morpho-constitutional analysis when collected.

\section{Keys for interpretation of stone analysis}

\section{Qualitative aspects}

The qualitative composition is imperative, and noncalcium-containing components are clinically relevant. Among purines:

Uric acid can be a marker for an excessive urate excretion in urine (hyperuricosuria), but it is more often related to insulin resistance with a defect in renal ammonia genesis and constant acidic urine. In less cases, it is related to a high urine concentration of urate because of low diuresis in patients treated a long time with uricosuric drugs or suffering inflammatory bowel disease that have required partial or total colectomy (digestive alkaline losses).

Uric acid may be identified as three different crystalline forms: anhydrous, monohydrate or dihydrate. There is no apparent difference between these three crystalline phases regarding the cause of the stone. However, uric acid dihydrate is the commonest crystalline phase of uric acid identified in crystalluria studies, and this phase is poorly stable with time, thus spontaneously converted to uric acid anhydrous after several weeks or months. Identifying uric acid dihydrate in a stone, especially as the principal form of uric acid, is highly suggestive of an active lithogenic process with recent stone formation.

In contrast, urate stones, irrespective to the cation that is linked to the urate anion, are always associated with an excessive urate concentration in urine because of low diuresis or high excretion of uric acid. Among the various urates reported, ammonium hydrogen urate and sodium hydrogen urate monohydrate are more frequent due to their relatively poor solubility. They are mainly found in alkaline urine. Sodium urate is seen in cases of high urate and high sodium concentration, while ammonium urate is observed with high ammonium concentration. The origin of ammonia is an overproduction by kidney cells as a compensatory mechanism of metabolic acidosis or a hydrolysis of urea by urea-splitting bacteria.

Dihydroxyadenine is a specific marker of an adenine phosphoribosyltransferase deficiency, a severe and rare genetic disease able to induce crystalline nephropathy and end-stage renal failure.

Xanthine suggests an overproduction of xanthine and/ or a defect on the oxidative pathway to convert it into uric acid. Two pathological conditions may be involved: an inherited deficiency in xanthine dehydrogenase (familial xanthinuria) and an enzyme inhibition by allopurinol therapy in patients suffering an accelerated purine metabolism pathway as in Lesh-Nyhan syndrome (hypoxanthine-guanine phosphoribosyltransferase deficiency).

Methyl-1 uric acid is one of the primary metabolites of caffeine. It is produced in the liver by enzymes of the cytochrome P450. For a not clearly understood reason, methyl-1 uric acid was only identified in patients with increased blood aluminum level because of chronic ingestion of aluminum-containing drugs. It should alert the physician on potential aluminum toxicity.

Other components without calcium can crystallize in the urine: cystine, struvite, other magnesium phosphates, proteins and various drugs.

Cystine is a marker of cystinuria, which is the most common inherited tubular defect inducing stone formation.

Struvite is an indicator of urinary tract infection by urea-splitting micro-organisms. Other magnesium salts, without ammonium ion, namely newberyite and trimagnesium phosphate pentahydrate may be considered as struvite derivatives related to past UTI.

Proteins are present in all stones in slight proportion, commonly $<5 \%$. In case they are more abundant, they must turn to particular causes of urolithiasis such as chronic pyelonephritis, severe chronic kidney disease, long-term treatment with some antiseptic or antiviral drugs. Among 
drugs able to form urinary stones, triamterene, atazanavir, sulfadiazine and ceftriaxone are the commonest. Ceftriaxone is identified in urinary or biliary tract as a calcium salt.

Regarding calcium oxalates and calcium phosphates, other criteria than the presence within the stone must be taking into account since these compounds are poorly soluble in urine. It is common to identify a small amount of carbapatite in the core of a calcium oxalate stone. The presence of carbapatite is of concern because it may be considered as the initiation process of the stone. It comes from Randall's plaque, a papillary calcification that serves as a nidus of a growing number of $\mathrm{CaOx}$ stones in industrialized countries [31-34].

In our experience, the proportion of stones exhibiting a papillary print (umbilicated) was high among COM stones $(39.6 \%)$ and low $(8.6 \%)$ among COD calculi $(p<0.0001)$. Randall's plaque among all spontaneously expulsed COM and COD stones were present in 60 and $16 \%$, respectively. Few data are available in other countries regarding the existence of Randall's plaque identified from stone analysis. For example, in Spain [35] and Balearic Islands [36], Randall's plaque was identified from stone examination in about $12.5 \%$ of cases. Of note, several reports based on ureteroscopic examination of the renal papillae of stone formers underlined the high occurrence of Randall's plaques in the kidneys, varying from $57 \%$ in France [34] to $75-80 \%$ in the USA $[33,37]$.

\section{Quantitative data}

Most reports on stone composition in the literature focus on the principal component. It is a simple and useful approach from an epidemiological point of view. However, it is important to consider qualitative and quantitative aspects of the stone structure (including minor components) and to know the distribution of these elements within the stone (and the corresponding morphology).

\section{Calcium oxalate}

$\mathrm{CaOx}$ represents the main chemical species of stones throughout the world, and it can be identified as three different crystalline phases: COM, the most common; COD, frequency depending on the countries; and calcium oxalate trihydrate (COT), named caoxite, a rare and unstable phase. The comparison between urine biochemistry and crystalline phase of $\mathrm{CaOx}$ found in freshly voided urine provided evidence that $\mathrm{COM}$ crystals are related to hyperoxaluria, while COD crystals are mainly related to hypercalciuria [21, 38-40]. Thus, COM stones are mainly associated with excessive oxalate concentration (low diuresis) and/or excessive oxalate excretion with secondary mild and intermittent hyperoxaluria in $88 \%$ of cases $[38,39,41]$.
By contrast, COD stones are related to hypercalciuria in more than $85 \%$ of cases [17]. The third phase (COT) is an infrequent and unstable form of $\mathrm{CaOx}$ and is observed in uncommon conditions including hyperoxaluria and specific drug intake [30, 42].

Among $\mathrm{CaOx}$ stones, a high proportion of them contains a mixture of COM and COD, often associated with carbapatite in various proportions (Randall's plaque excluded). In such cases, biochemical factors involved in stone formation are those involved for each crystalline phase, i.e., hypercalciuria and hyperoxaluria. If an increased content of carbapatite is present, it should orient to more specific metabolic dysfunctions such as bone resorption, primary hyperparathyroidism, acidification tubular defect or another alkalinizing source.

\section{Calcium phosphate}

$\mathrm{CaPh}$ is a common chemical component of stones identified in about $85 \%$ of all calculi in our experience (proportion: 0.5 up to $99 \%$ ). The clinical significance depends on the crystalline phase, the location and the overall content within the stone. Previously was underlined the increasing part of carbapatite Randall's plaque as a nidus for $\mathrm{CaOx}$ stones. In such cases, the $\mathrm{CaPh}$ content is low $(<5 \%$; Fig. 1). As suggested by Miller and coworkers, other $\mathrm{CaOx}$ stones which contain a core of carbapatite without papillary print may also result from an initiation on Randall's plaque with a secondary coverage of the plaque by new layers of $\mathrm{CaOx}$ after the stone was unhooked from the papilla [43]. However, other causes of $\mathrm{CaPh}$ should be considered. Because carbapatite is highly $\mathrm{pH}$ dependent, it must be expected that carbapatite-rich stones are developed in poorly acidic to alkaline urine. This is suggestive for either urinary tract infection (UTI) or metabolic disorders responsible for chronically elevated urine $\mathrm{pH}$, associated or not with hypercalciuria $[44,45]$. Carbapatite associated with brushite and/or octacalcium phosphate pentahydrate (OCPP) is commonly a marker of hypercalciuria. Presence of OCPP indicates an active and recent lithogenic process [18].

UTI is one of the most common mechanisms resulting in phosphate stones [17, 44]. In such cases, several characteristics of the stone should be considered:

1. In addition to carbapatite, other $\mathrm{CaPh}$ species are present in the stone, in particular amorphous carbonated calcium phosphate and/or whitlockite.

2. A specific sign of UTI-induced calculi is the presence of struvite.

3. In the absence of struvite, another sign may be useful, namely the carbonation rate of carbapatite as determined by infrared spectroscopy [46]. When it is higher 
than $15 \%$, the probability that UTI is a driving force for stone formation is very high.

Carbapatite is rarely pure, and other crystalline phases present as minor components may assist to establish the diagnosis. Carbapatite associated with COD is highly suggestive of hypercalciuria and should raise suspicion for primary hyperparathyroidism [47]. In contrast, carbapatite associated with COM is more related to medullary sponge kidney and other causes of urinary stasis.

Among metabolic causes of carbapatite-rich stones, hypercalciuria is an important factor, the mechanism of which being often resorptive and/or absorptive [44, 48, 49]. Primary hyperparathyroidism is one of the main causes of
Fig. 7 Examples of brushite stones type IVd (left surface; right section)
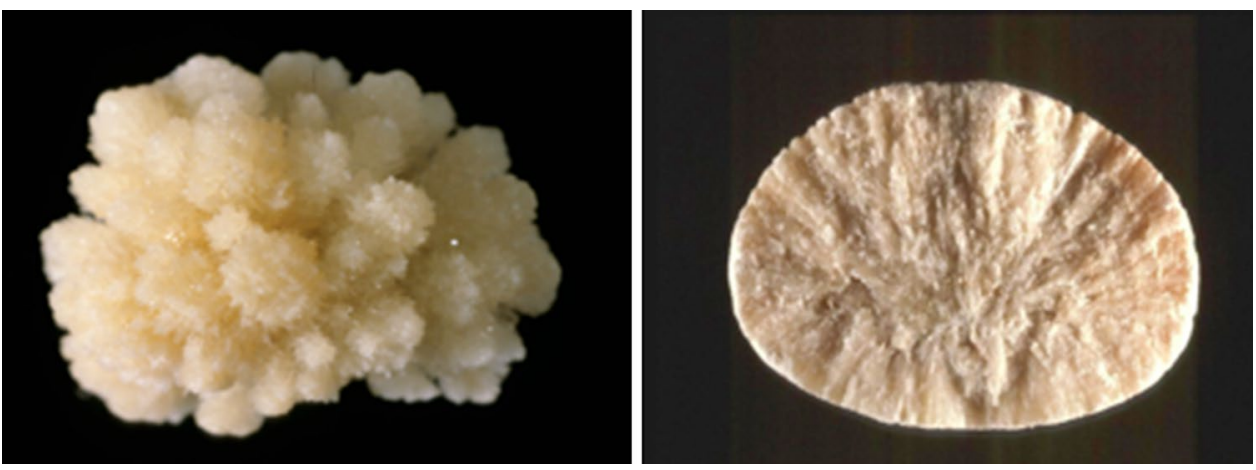

Fig. 8 Calcium phosphate stones mainly composed of carbapatite: a subtype IVa1 (surface); b subtype IVa1 (section); c subtype IVa2 (surface): note the glazed aspect and the presence of very tiny cracks; d subtype IVa2 (section); e subtype IVb (surface); f subtype IVb (section)
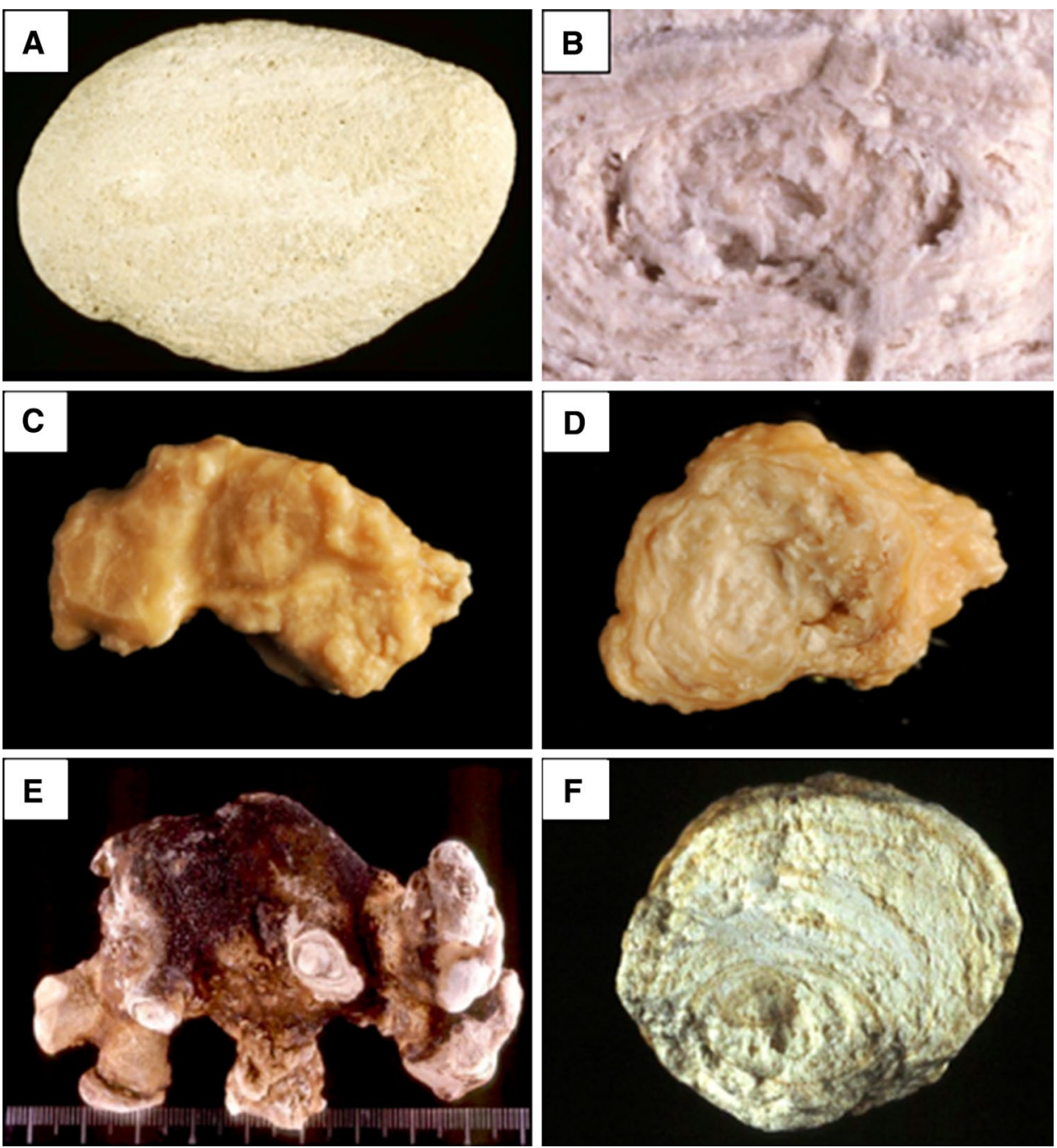
resorptive hypercalciuria. Kidney stones related to such a pathological condition were recently considered, revealing particular features in stone composition and morphology (Figs. 6, 7) [47].

An infrequent cause of $\mathrm{CaPh}$ stones is a kidney cells impairment to excrete protons as observed in inherited distal acidification defect or acquired auto-immune diseases such as Sjogren's syndrome. In such metabolic diseases, urinary calculi are mainly composed of carbapatite with a very high content of $\mathrm{CaPh}$, often above $80 \%$ of the stone mass. While most causes of carbapatite stones induce IVa1 or IVb subtype, distal acidification defects are associated with IVa2 subtype in $90 \%$ of cases (Fig. 8) [9]. Such findings illustrate the significance of morpho-constitutional analysis helping to find clinical diagnosis.

\section{The significant contribution of the stone morphology}

\section{COM stones}

COM accounts in most countries over the world as the more common and more abundant component of stones [50-53]. The morphological aspect of COM stones orients toward very different diseases or lithogenic conditions:

- Mild intermittent hyperoxaluria related to high oxalate intake

- Low diuresis with increased concentration of oxalate ions in urine

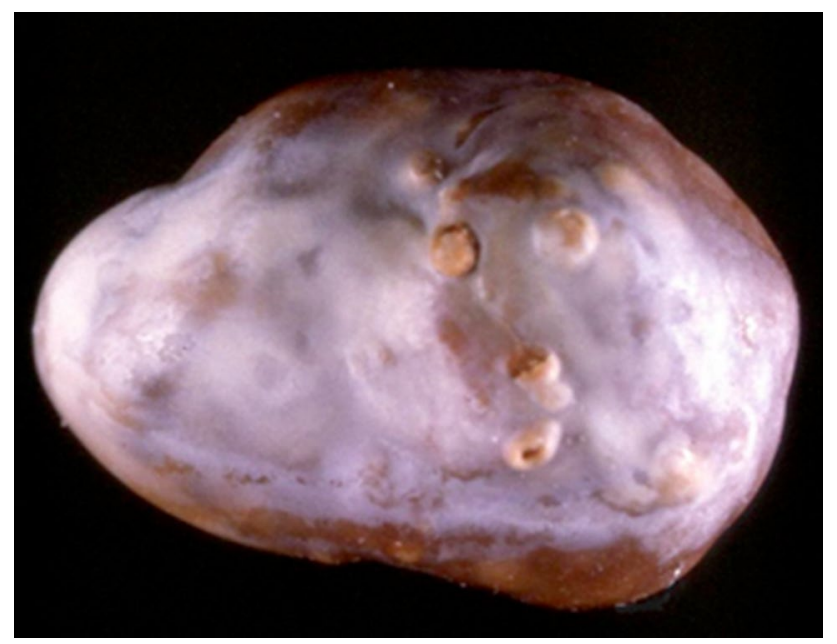

Fig. 9 COM stone subtype Ia. Note the thin grayish layer of very recently deposited crystals covering the brown surface of the stone. Such a grayish coverage is resulting from recent episode of hyperoxaluria often related to transient oxalate-rich food intake
- Heavy hyperoxaluria either related to inherited diseases (primary hyperoxaluria type 1) or to enteric hyperoxaluria (ileal resection, bariatric surgery or chronic pancreatitis).

COM stones exhibit five different morphologies in class I of the morpho-constitutional classification.

The subtype Ia (Fig. 1), often dark brown in color, suggests a slow and intermittent growth related to peaks of hyperoxaluria (low diuresis or oxalate-rich food intake). It is the most common subtype of calcium stones in most countries (unpublished data). While seeing a grayish thin layer on a Ia stone surface, it corresponds to a freshly COM crystal sediments secondary to a recent peak of urine concentration of oxalate (Fig. 9).

The subtype Ib (Fig. 10) can be a marker of an old stone, probably first developed as weddellite because of transient hypercalciuria and secondly completely converted from weddellite to whewellite in the time. Subtypes Ia and Ib are often dark brown in color.

In contrast, subtype Ic is very light, brown-yellow pale, or even white in children (Fig. 11). It is associated
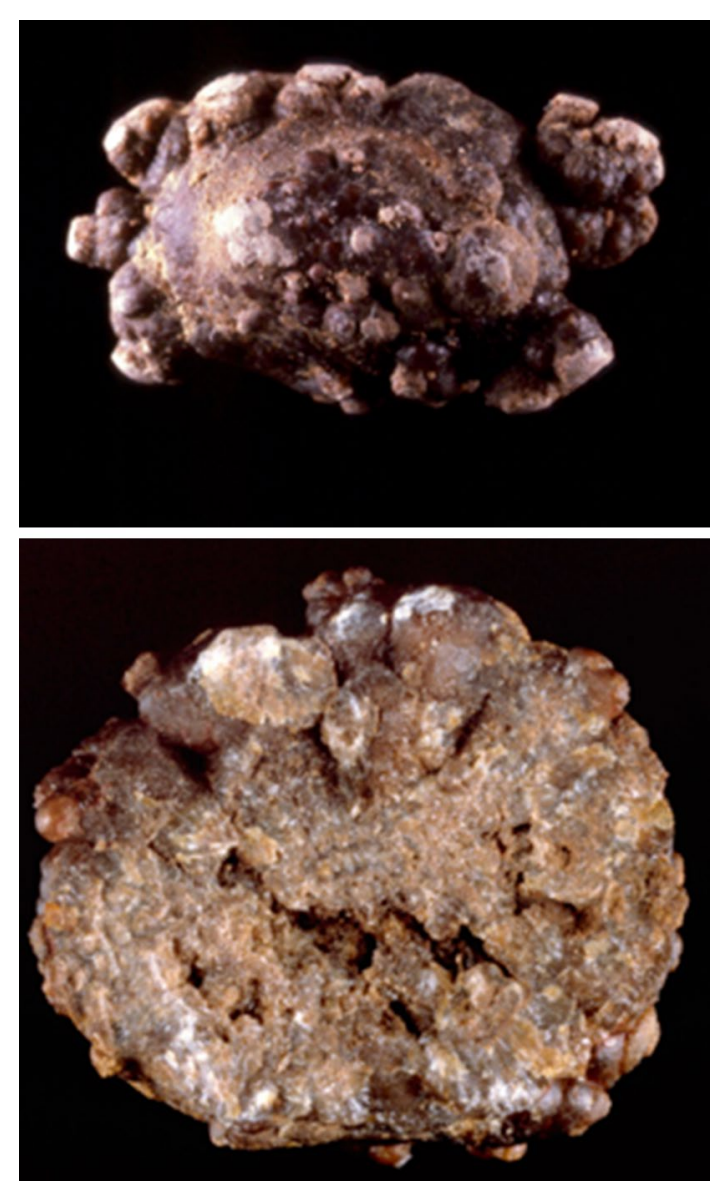

Fig. 10 COM stones subtype Ib. Top surface, bottom section. Note the dark color of the stone in most parts of surface and section 
with heavy oxaluria, mainly primary hyperoxaluria type 1 (related to alanine glyoxylate aminotransferase deficiency in hepatocytes), which is the most severe stone disease often responsible for end-stage renal failure, especially when the diagnosis was delayed because stone morphology was not considered [54, 55]. All 92 stones from patients with PH type 1 analyzed in our laboratory had this Ic morphology, which appears to be virtually pathognomonic for the disease. Therefore, this particular morphology of pure COM stones should immediately orient the physician toward this severe disease to allow early introduction of proactive therapeutic strategy.

Other genetic forms of primary hyperoxaluria such as hyperoxaluria type 2 (glyoxylate reductase/hydroxypyruvate reductase deficiency) [56] or hyperoxaluria type 3 (related to a dysfunction of the 4-hydroxy 2-oxoglutarate aldolase in the hydroxyproline pathway) [57] do not present every time subtype Ic since hyperoxaluria is often associated with hypercalciuria for a not yet understood reason [58].

The subtype Id is typically a marker for stasis in patients with hyperoxaluria in a confined environment such as: calyceal diverticulum, ureteropelvic junction obstruction or prostate hypertrophy with incomplete bladder emptying (bladder stones).

Finally, the subtype Ie is related to severe forms of enteric hyperoxaluria in patients suffering from inflammatory bowel
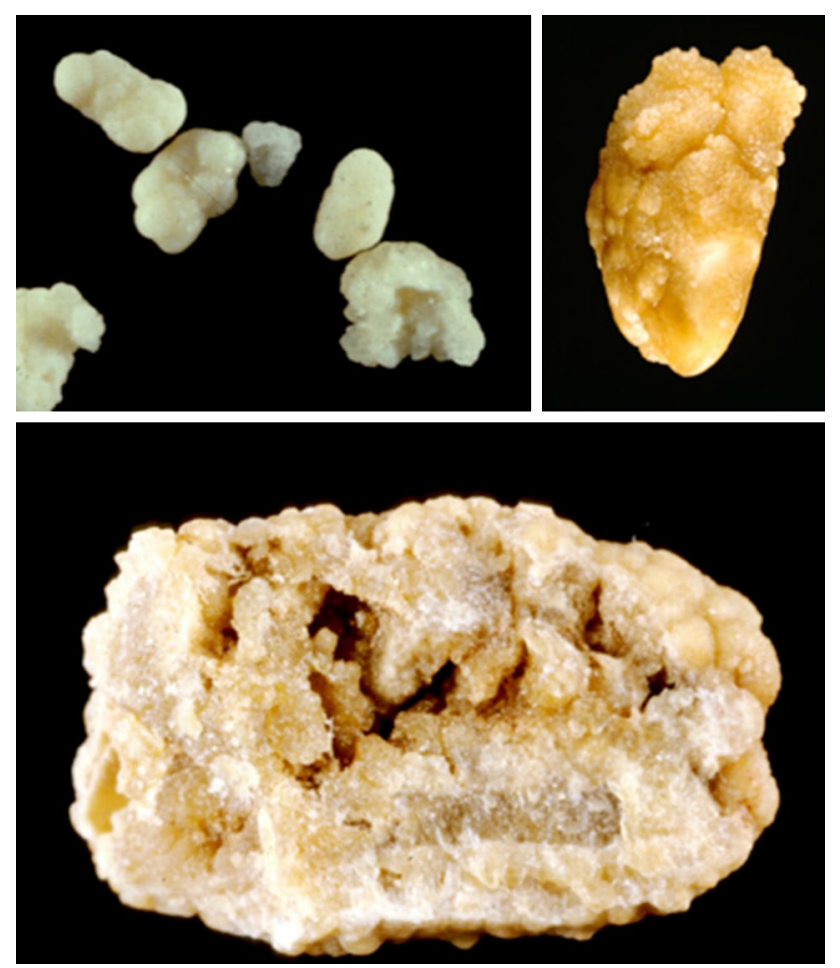

Fig. 11 COM stones subtype Ic. Top surface. On the left side, the stones are whitish. They came from an infant aged $<2$ years. Bottom section. Note the very light color in most parts of the stones diseases with extensive ileal resections, bariatric surgery or chronic pancreatitis (Fig. 12) [9]. Among patients having enteric hyperoxaluria, subtype Ie was present in $82.5 \%$ of cases.

Although Ic and Ie subtypes stones are scarce, it is important to identify these subtypes since they warn the clinician of a severe cause of hyperoxaluria, not always previously identified with investigations, and often responsible for a progressive kidney failure.

\section{COD stones}

Weddellite stones correspond to type II of the classification. Subtypes IIa to IIc are often related to hypercalciuria either associated or not with other conditions favoring stones growth. For example, we found that IIa or IIb subtypes made of large COD crystals were frequently related to hypercalciuria associated with hyperoxaluria and relative hypocitraturia (Fig. 13).

\section{Uric acid and urate stones}

Remember that uric acid and urates account for type III of the classification and include four subtypes. Among them,
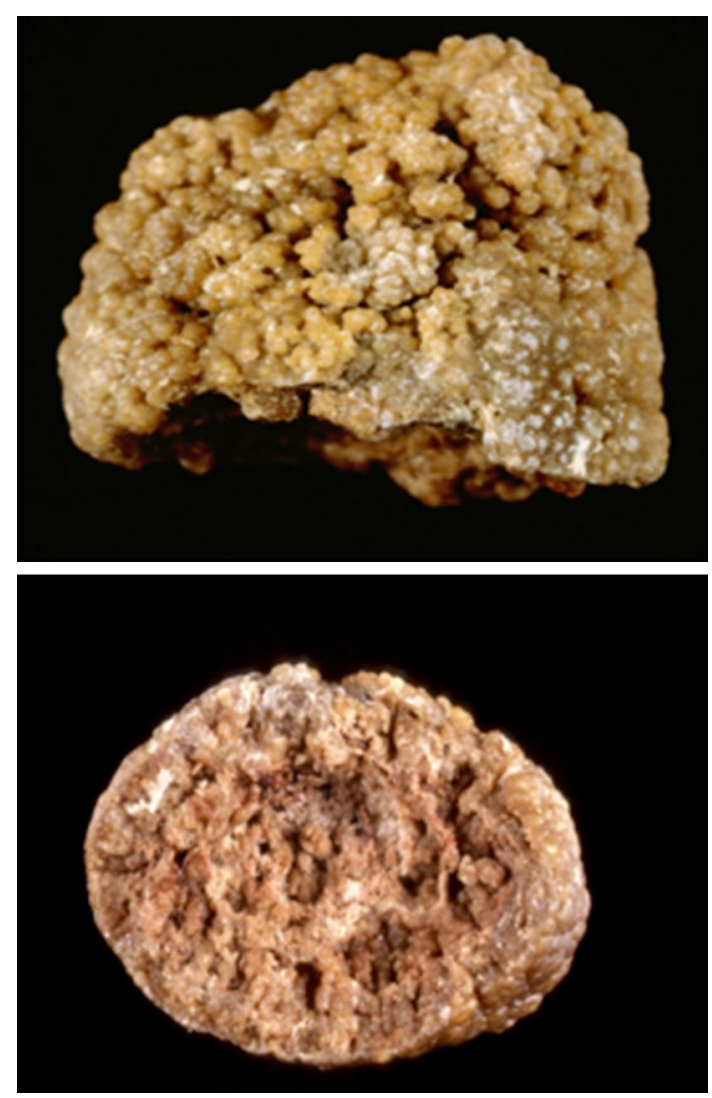

Fig. 12 COM stones subtype Ie. Top surface, bottom section 

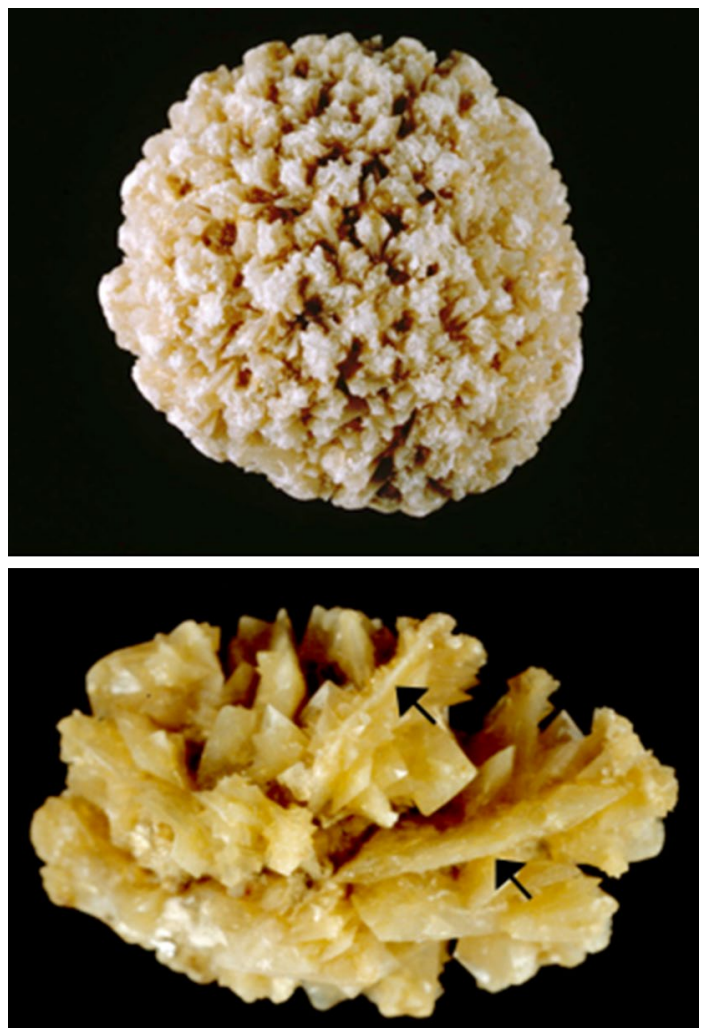

Fig. 13 COD stones subtype IIa. Top stone made of small octahedral crystals of weddellite as commonly observed in patients who form stones because hypercalciuria. Bottom stone made of both small and very large crystals (arrows) of weddellite as commonly found in patients who suffered hypercalciuria, hyperoxaluria and, often mild hypocitraturia

subtypes IIIa and IIIb gather uric acid stones and subtypes IIIc and IIId gather urate stones that are commonly composed of ammonium hydrogen urate, which is the less soluble form of urate salts in urine.

Regarding uric acid stones, the subtype IIIa is primarily related to slow stone growth conditions as observed in urinary stasis and is mainly found with bladder stone of men with prostate hypertrophy (Fig. 14) By contrast, IIIb subtype suggests a substantial involvement of a metabolic process associated with one or several of the following factors:

- Permanent low urine $\mathrm{pH}$ in the case of metabolic syndrome or type 2 diabetes mellitus, or in the case of intestinal alkali loss in patients having chronic hydroelectrolytic diarrhea (ileostomy, colectomy, hemorrhagic rectocolitis,...)

- High excretion of uric acid as observed in diabetes mellitus, in myelo- or lymphoproliferative syndromes or the case of Vaquez disease or rare cases of tubular dysfunction inducing a defect in urate reabsorption. Of note,
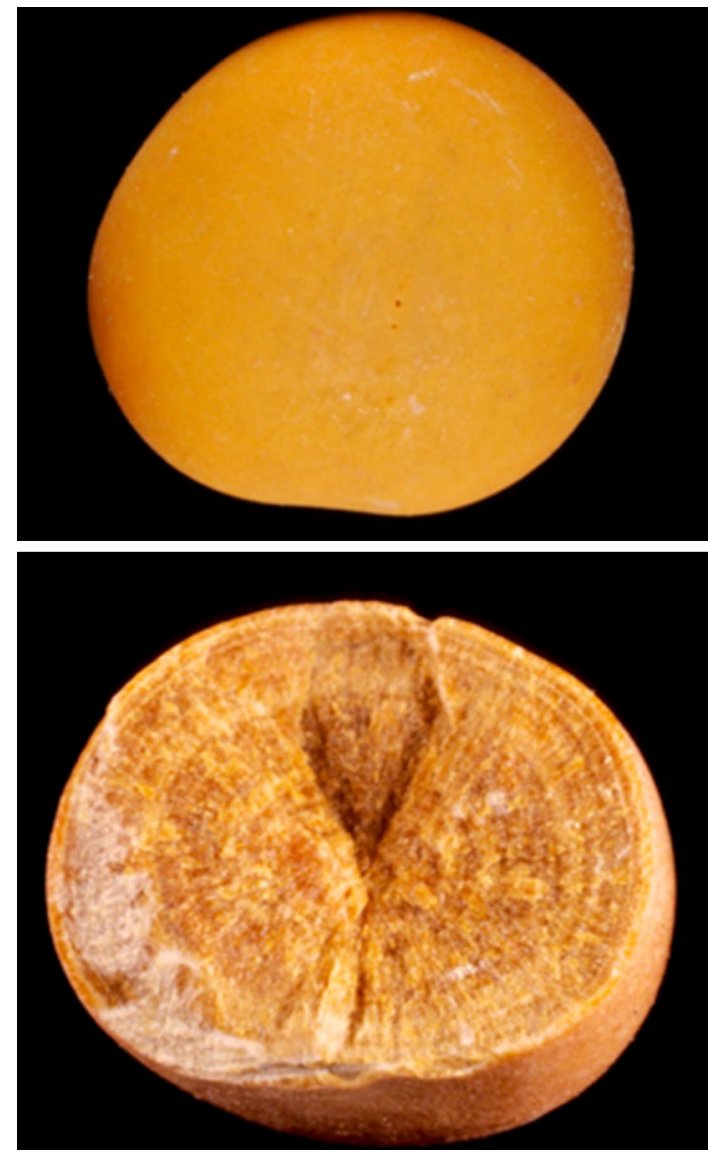

Fig. 14 Uric acid stone subtype IIIa. Top surface, bottom section

among patients suffering type 2 diabetes, females are especially at risk to develop uric acid stones exhibiting a subtype IIIb (37 vs. $13 \%$ in the absence of diabetes, $p<0.00001)$.

- High production and excretion of uric acid from diet origin (high fructose intake, nucleo-protein rich food, rare genetic diseases on the nucleotide pathways such as Lesh-Nyhan syndrome or phosphoribosylpyrophosphate synthetase hyperactivity).

- High uric acid concentration in acidic and concentrated urine secondary to low diuresis, whatever the origin.

In all cases, the high content of uric acid dihydrate in a IIIb stones is a marker of an active lithogenic process and a recent growth of the stone (Fig. 15).

Subtypes IIIc and IIId gather urate stones that have different etiologies than these observed for uric acid stones. In contrast with IIIa and IIIb stones, urate calculi are not developed in acidic urine and require a high urine concentration of urate in poorly acidic to alkaline urine. The main causes for urate stones are alkalizing conditions related to therapeutic measures or to urinary tract infection by urea-splitting micro-organisms or high urate concentration with low 

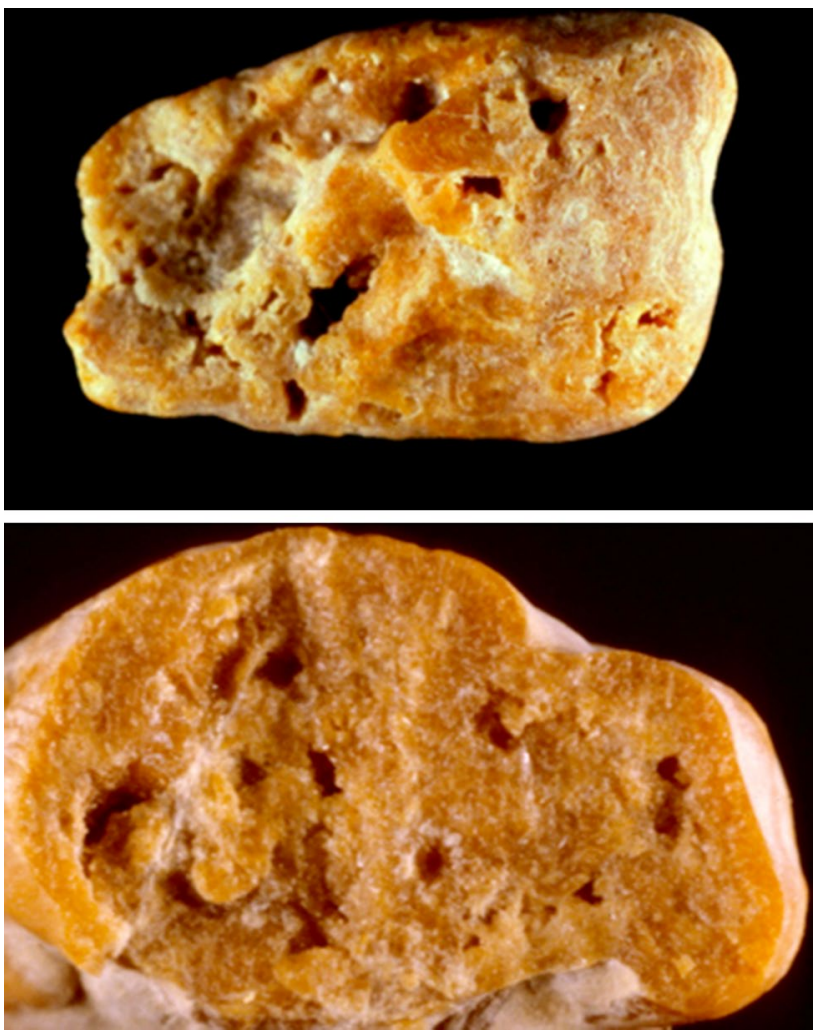

Fig. 15 Uric acid stone subtype IIIb. Top surface, bottom section

content of electrolytes in urine as found in chronic diarrhea. Among urate salts, ammonium urate is the most common component of IIIc subtype and the only one of IIId subtype.

The commonest form observed in Western countries corresponds to IIIc subtype calculi with a homogenous rough surface with local porous areas. The color is usually grayish. The inner structure is commonly loose, unorganized, and locally porous, the color being the same as in the surface. Such type of ammonium urate is found mainly in two pathological conditions:

- Local production of ammonium ions from urea in patients with UTI by urea-splitting bacteria;

- Excessive alkaline urine secondary to alkalinization for dissolving radiolucent stones (uric acid stone suspected) in patients with a preexisting hyperuricosuria.

The subtype IIId is seen among ammonium urate stones of children (mainly boys) with the endemic bladder lithiasis living in developing countries and anorectic patients living in industrialized countries. The inner structure of the stone is typical and appears as alternate concentric thick and thin layers, the former being compact and brownish, whereas the latter is loose and locally porous, beige in color. This stone subtype is perceived in cases of base loss due to chronic diarrhea with low phosphate intake, resulting in a compensatory increase in urinary ammonia excretion. The causes of diarrhea may be of infectious origin or laxative abuse in anorectic patients [59,60]. Stone color observed with laxative abuse is very dark with purplish shades. In patients who have chronic diarrhea and ammonium urate stones, the subtype in more than $90 \%$ of cases was IIId [9].

\section{Conclusion}

Routine morpho-constitutional analysis of stones by morphologic examination combined with FTIR or X-ray diffraction considerably improves information from the stone analysis to determine the cause(s) of stone disease. It should be recommended in all laboratories that provide stone analysis for helping physicians to identify the causes of urolithiasis. It is remarkable that stones with the same chemical composition exhibit distinct morphological characteristics according to their cause, in relation with the degree of metabolic abnormalities and the kinetics of the lithogenic process.

Conflict of interest Olivier Traxer is a consultant for Coloplast, Rocamed, Olympus and AMS. Jonathan Cloutier, Luca Villa and Michel Daudon have nothing to disclose.

Ethical standards The manuscript does not contain clinical studies. All patients described with the figure in this manuscript have given an informed consent.

Open Access This article is distributed under the terms of the Creative Commons Attribution License which permits any use, distribution, and reproduction in any medium, provided the original author(s) and the source are credited.

\section{References}

1. Soucie JM, Coates RJ, McClellan W, Austin H, Thun M (1996) Relation between geographic variability in kidney stones prevalence and risk factors for stones. Am J Epidemiol 143:487-495

2. Ekane S, Wildschutz T, Simon J, Schulman CC (1997) Lithiase urinaire : épidémiologie et physiopathologie. Acta Urol Belg 65:1-8

3. Trinchieri A, Coppi F, Montanari E, Del Nero A, Zanetti G, Pisani E (2000) Increase in the prevalence of symptomatic upper urinary tract stones during the last ten years. Eur Urol 37:23-25

4. Hesse A, Brandle E, Wilbert D, Kohrmann KU, Alken P (2003) Study on the prevalence and incidence of urolithiasis in Germany comparing the years 1979 vs 2000. Eur Urol 44:709-713

5. Lee YH, Huang WC, Tsai JY, Lu CM, Chen WC, Lee MH et al (2002) Epidemiological studies on the prevalence of upper urinary calculi in Taiwan. Urol Int 68:172-177

6. Robertson WG, Peacock M (1982) The pattern of urinary stone disease in Leeds and in the United Kingdom in relation to animal protein intake during the period 1960-1980. Urol Int 37:394-399

7. Borghi L, Schianchi T, Meschi T, Guerra A, Allegri F, Maggiore U, Novarini A (2002) Comparison of two diets for the prevention 
of recurrent stones in idiopathic hypercalciuria. N Engl J Med 346(2):77-84

8. Taylor EN, Curhan GC (2008) Fructose consumption and the risk of kidney stones. Kidney Int 73:207-212

9. Daudon M, Jungers P (2012) Stone composition and morphology: a window on etiology. In: Talati JJ, Tiselius HG, Albala DM, Ye Z (eds) Urolithiasis: basic science and clinical practice. Springer, London, pp 113-140

10. Simmonds HA (1986) 2,8-dihydroxyadenine lithiasis. Clin Chim Acta 160:103-108

11. Ceballos-Picot I, Perignon JL, Hamet M et al (1992) 2,8-dihydroxyadenine urolithiasis, an underdiagnosed disease. Lancet 339:1050-1051

12. Bollée G, Harambat J, Bensman A, Knebelmann B, Daudon M, Céballos-Picot I (2012) Adenine phosphoribosyltransferase deficiency. Clin J Am Soc Nephrol 7(9):1521-1527

13. Daudon M, Estépa L, Viard JP, Joly D, Jungers P (1997) Urinary stones in HIV-1-positive patients treated with indinavir. Lancet 349:1294-1295

14. Daudon M, Jungers P (2004) Drug-induced renal calculi: epidemiology, prevention and management. Drugs 64:245-275

15. Couzigou C, Daudon M, Meynard JL et al (2007) Urolithiasis in HIVpositive patients treated with atazanavir. Clin Infect Dis 45:e105-e108

16. Daudon M, Réveillaud RJ (1984) Whewellite and weddellite: toward different etiopathogenesis. Interest of the morphological typing of the stones. Néphrologie 5:195-201 (in French)

17. Maurice-Estepa L, Levillain P, Lacour B, Daudon M (1999) Crystalline phase differentiation in urinary calcium phosphate and magnesium phosphate calculi. Scand J Urol Nephrol 33:299-305

18. Méria P, Hadjadj H, Jungers P, Daudon M, Members of the Urolithiasis Committee of the French Urological Association (2010) Stone formation and pregnancy: pathophysiological insights gained from morphoconstitutional stone analysis. J Urol 183(4):1412-1416

19. Daudon M (2005) Épidémiologie actuelle de la lithiase rénale en France. Ann Urol 39:209-231

20. Daudon M, Bader CA, Jungers P (1993) Urinary calculi: review of classification methods and correlations with etiology. Scanning Microsc 7:1081-1106

21. Asplin JR, Lingeman J, Kahnoski R, Mardis H, Parks JH, Coe FL (1998) Metabolic urinary correlates of calcium oxalate dihydrate in renal stones. J Urol 159:664-668

22. Hesse A, Kruse R, Geilenkeuser WJ, Schmidt M (2005) Quality control in urinary stone analysis: results of 44 ring trials (19802001). Clin Chem Lab Med 43:298-303

23. Bastian PJ, Lorken M, Euler H, Lummen G, Bastian HP (2008) Results of the evaluation of 85,337 urinary stone analyses. Aktuelle Urol 39:298-304

24. Estepa L, Daudon M (1997) Contribution of fourier transform infrared spectroscopy to the identification of urinary stones and kidney crystal deposits. Biospectroscopy 3:347-369

25. Hidalgo A, Santos M, Carmina P, Garcia-Ramos JV, Bellanato J, Cifuentes Delatte L (1983) Analisis de calculos urinarios por espectroscopia infraroja y Raman. Instituto de Optica (Daza de Valdes) C.S.I.C, Madrid

26. Nguyen Quy D, Daudon M (1997) Infrared and Raman spectra of calculi. Elsevier, Paris

27. Marickar YM, Lekshmi PR, Varma L, Koshy P (2009) EDAX versus FTIR in mixed stones. Urol Res 37(5):271-276

28. Sharma RN, Shah I, Gupta S, Sharma P, Beigh AA (1989) Thermogravimetric analysis of urinary stones. Br J Urol 64:564-566

29. Lee TT, Elkoushy MA, Andonian S (2014) Are stone analysis results different with repeated sampling? Can Urol Assoc J 8(5-6):E317-E322
30. Daudon M, Réveillaud RJ, Normand M, Petit C, Jungers P (1987) Piridoxilate-induced calcium oxalate calculi: a new drug-induced metabolic nephrolithiasis. J Urol 138:258-261

31. Evan AP, Lingeman JE, Coe FL et al (2003) Randall's plaque of patients with nephrolithiasis begins in basement membranes of thin loops of Henle. J Clin Invest 111:607-616

32. Daudon M, Traxer O, Jungers P, Bazin D. Stone morphology suggestive of Randall's plaque. In Evan AP, Lingeman JE, Williams JC Jr (eds) Renal stone disease. American Institute of physics conference proceedings, Melville, New York 2007, vol 900, pp. 26-34

33. Matlaga BR, Coe FL, Evan AP, Lingeman JE (2007) The role of Randall's plaques in the pathogenesis of calcium stones. J Urol 177:31-38

34. Daudon M, Traxer O, Williams JC, Bazin DC (2011) Randall's plaques. In: Rao PN, Preminger GM, Kavanagh JP (eds) Urinary tract stone disease. Springer, London, pp 103-112

35. Cifuentes Delatte L, Minon-Cifuentes J, Medina JA (1987) New studies on papillary calculi. J Urol 137:1024-1029

36. Grases F, Costa-Bauza A, Ramis M, Montesinos V, Conte A (2002) Simple classification of renal calculi closely related to their micromorphology and etiology. Clin Chim Acta 322:29-36

37. Low RK, Stoller ML (1997) Endoscopic mapping of renal papillae for Randall's plaques in patients with urinary stone disease. $\mathbf{J}$ Urol 158:2062-2064

38. Daudon M, Jungers P (2004) Clinical value of crystalluria and quantitative morpho-constitutional analysis of urinary calculi. Nephron Physiol 98:31-36

39. Daudon M, Labrunie M, Hennequin C, Lacour B, Jungers P (1997) Relative influence of calcium and oxalate urine concentration on the risk of calcium oxalate crystallization. In: Jungers P, Daudon M (eds) Renal stone disease. Crystallization process, pathophysiology, metabolic disorders and prevention. Elsevier, Paris, pp 72-73

40. Daudon M, Jungers P, Bazin D (2008) Peculiar morphology of stones in primary hyperoxaluria. N Engl J Med 359(1):100-102

41. Daudon M, Jungers P, Bazin D. Stone morphology: implication for pathogenesis. In: Evan AP, Lingeman JE, McAteer JA and Williams JC Jr (eds), Renal stone disease 2, American Institute of physics conference proceedings, Melville, New York 2008, vol 1049, pp. 199-215

42. Daudon M, Réveillaud RJ, Jungers P (1985) Piridoxilate-associated calcium oxalate urinary calculi: a new metabolic druginduced nephrolithiasis. Lancet 8441:1338

43. Miller NL, Williams JC Jr, Evan AP et al (2009) In idiopathic calcium oxalate stone-formers, unattached stones show evidence of having originated as attached stones on Randall's plaque. BJU Int 105:242-245

44. Gault MH, Paul MD, Longerich L (1990) Comparison of urinary tract infection in calcium oxalate and calcium phosphate stone formers. Nephron 55:408-413

45. Daudon M, Bouzidi H, Bazin D (2010) Composition and morphology of phosphate stones and their relation with etiology. Urol Res 38:459-467

46. Carpentier X, Daudon M, Traxer O et al (2009) Relationships between carbonation rate of carbapatite and morphologic characteristics of calcium phosphate stones and etiology. Urology 73(5):968-975

47. Bouzidi H, de Brauwere D, Daudon M (2011) Does urinary stone composition and morphology help for prediction of primary hyperparathyroidism? Nephrol Dial Transplant 26:565-572

48. Pak CY, Nicar MJ, Peterson R et al (1981) A lack of unique pathophysiologic background for nephrolithiasis of primary hyperparathyroidism. J Clin Endocrinol Metab 53:536-542

49. Parks JH, Coe FL, Evan AP et al (2009) Clinical and laboratory characteristics of calcium stone-formers with and without primary hyperparathyroidism. BJU Int 103:670-678 
50. Osther PJS (2012) Epidemiology of kidney stones in the European Union. In: Talati JJ, Tiselius HG, Albala DM, Ye Z (eds) Urolithiasis: basic science and clinical practice. Springer, London, pp 3-12

51. Ganesamoni R, Singh SK (2012) Epidemiology of stone disease in Northern India. In: Talati JJ, Tiselius HG, Albala DM, Ye Z (eds) Urolithiasis: basic science and clinical practice. Springer, London, pp 39-46

52. Rodgers A (2012) Epîdemiology: South-Africa and sub-Saharan Africa. In: Talati JJ, Tiselius HG, Albala DM, Ye Z (eds) Urolithiasis: basic science and clinical practice. Springer, London, pp $67-71$

53. Korkes F, Schor N, Pfeferman Heilberg I (2012) Epidemiology of stone disease in South America. In: Talati JJ, Tiselius HG, Albala DM, Ye Z (eds) Urolithiasis: basic science and clinical practice. Springer, London, pp 61-66

54. Danpure CJ, Jennings PR, Watts RW (1987) Enzymological diagnosis of primary hyperoxaluria type 1 by measurement of hepatic alanine: glyoxylate aminotransferase activity. Lancet 1:289-291

55. Cochat P, Hulton SA, Acquaviva C et al (2012) Primary hyperoxaluria Type 1: indications for screening and guidance for diagnosis and treatment. Nephrol Dial Transplant 27:1729-1736
56. Rumsby G, Sharma A, Cregeen DP, Solomon LR (2001) Primary hyperoxaluria type 2 without L-glycericaciduria: is the disease under-diagnosed? Nephrol Dial Transplant 16:1697-1699

57. Riedel TJ, Johnson LC, Knight J, Hantgan RR, Holmes RP, Todd Lowther W. Structural and Biochemical Studies of Human 4-hydroxy-2-oxoglutarate Aldolase: Implications for Hydroxyproline Metabolism in Primary Hyperoxaluria. Plos One 2011; 6 (10):1-15, e26021

58. Monico CG, Rossetti S, Belostotsky R et al (2011) Primary hyperoxaluria type III gene HOGA1 (formerly DHDPSL) as a possible risk factor for idiopathic calcium oxalate urolithiasis. Clin J Am Soc Nephrol 6:2289-2295

59. Dick WH, Lingeman JE, Preminger GM, Smith LH, Wilson DM, Shirrell WL (1990) Laxative abuse as a cause for ammonium urate renal calculi. J Urol 143:244-247

60. Kato Y, Hou K, Saga Y, Yamaguchi S, Yachiku S, Kawakami N (2004) Ammonium acid urate stone due to laxative abuse: a case report. Hinyokika Kiyo 50:799-803 (in Japanese) 